University of Tennessee Health Science Center UTHSC Digital Commons

Spring 5-12-2021

\title{
Effects of Social Determinants of Health in Progression to Type 2 Diabetes
}

Folabi I. Ariganjoye

University of Tennessee Health Science Center

Follow this and additional works at: https://dc.uthsc.edu/hiimappliedresearch

Part of the Community Health and Preventive Medicine Commons, Endocrine System Diseases Commons, Endocrinology, Diabetes, and Metabolism Commons, Health and Medical Administration Commons, Health Information Technology Commons, Health Services Research Commons, Investigative Techniques Commons, Medical Nutrition Commons, Nutritional and Metabolic Diseases Commons, Other Medical Sciences Commons, and the Preventive Medicine Commons

\section{Recommended Citation}

Ariganjoye, Folabi I., "Effects of Social Determinants of Health in Progression to Type 2 Diabetes" (2021). Applied Research Projects. 76. . https://doi.org/10.21007/chp.hiim.0073

https://dc.uthsc.edu/hiimappliedresearch/76

This Research Project is brought to you for free and open access by the Department of Health Informatics and Information Management at UTHSC Digital Commons. It has been accepted for inclusion in Applied Research Projects by an authorized administrator of UTHSC Digital Commons. For more information, please contact jwelch30@uthsc.edu. 
Running head: SOCIAL DETERMINANTS OF HEALTH IN PROGRESSION TO TYPE 2 DIABETES

Effects of Social Determinants of Health in Progression to Type 2 Diabetes

Folabi I. Ariganjoye

University of Tennessee Health Science Center

Master of Health Informatics and Information Management

Advisor: Charisse Madlock-Brown, Ph.D.

April 2021 
SOCIAL DETERMINANTS OF HEALTH IN PROGRESSION TO TYPE 2 DIABETES

This is dedicated to my beloved family, you deserved this. Thank you for all the support. You all gave me a reason to keep surging forward. 
SOCIAL DETERMINANTS OF HEALTH IN PROGRESSION TO TYPE 2 DIABETES

\section{Acknowledgments}

I would like to express my gratitude to Dr. Charisse Madlock-Brown who guided this research. Introducing me to TriNetX was in no small measure contributed to the timeliness of this paper. My profound gratitude also goes to the faculty at the Cahaba Family Medicine residency program for accommodating me, without whom this research would not have been possible. My mentors at the Endocrinology Division of the University of Tennessee Health Science Centre helped lay a good foundation for this research.

Lastly to friends and family, I appreciate the moral support, it kept me going. 
SOCIAL DETERMINANTS OF HEALTH IN PROGRESSION TO TYPE 2 DIABETES

\begin{abstract}
The prevalence of prediabetes and diabetes in the United States and around the world has increased faster than expected in the last 30 years. The economic burden this costs a nation can be astronomic both in terms of expense and loss in productivity. One-third of U.S. adults, 86 million people, have prediabetes. Effective management is needed that can reach these 86 million, and others at high risk, to reduce their progression to diagnosed Type 2 diabetes. After the literature review, there was not enough literature to support how these led to the progression to diabetes. The abundant literature is centered on how to prevent complications and improve the quality of life of those living with type 2 diabetes. This paper will focus on the longitudinal association between these social determinants and how they may predispose to the progression to Type 2 diabetes. Keywords: Prediabetes, Normoglycemia, Type 2 Diabetes, Social Determinants of Health, ICD-10 Z-codes
\end{abstract}




\section{Table of Contents}

Dedication.............................................................

Acknowledgment..................................................ii

Abstract.....................................................................

Table of Contents......................................................

List of Tables..........................................................

List of Figures................................................. vi

Chapter One........................................................

Introduction....................................................

Background of the Problem......................................

Research Questions...........................................5

Definition of Terms.............................................5

Limitations of study........................................6

Chapter Two.........................................................

Review of Literature...........................................

Summary of Chapter............................................. 9

Chapter Three...................................................... 10

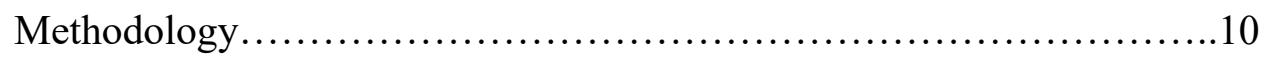

Population and Sample Design..................................10

Data Collection Procedures..................................... 10

Data Collection Instrument......................................11

Data Analysis................................................11

Chapter Four...................................................... 12 
Results................................................... 12

Results of Research Questions....................................23

Chapter Five......................................................24

Discussions................................................... 24

Conclusions................................................... 24

Recommendations..........................................26

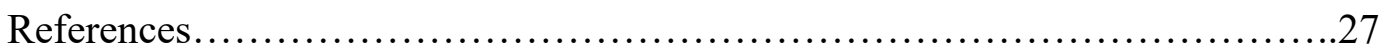

Table

Table 1 - SDoH table after outcome measure ............................18

\section{List of Figures}

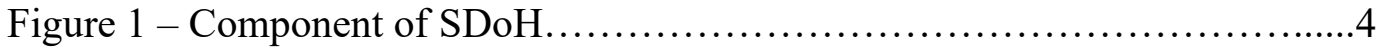

Figure 2 - Exposed cohort after four-year follow-up ........................ 12

Figure 3 - Non-exposed cohort after four-year follow-up...................13

Figure 4 - Demography of exposed cohort............................. 14

Figure 5 - Demography of non-exposed cohort......................... 15

Figure $6 \mathrm{a}-$ Risk difference of the primary outcome........................ 16

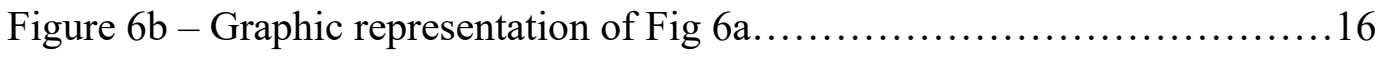

Figure $7 \mathrm{a}-\log$ Rank Test of the primary outcome.........................17

Figure $7 b$ - Kaplan-Meier curve for the primary outcome.................... 17

Figure $8 \mathrm{a}-\mathrm{Z} 65$ outcomes....................................... 19

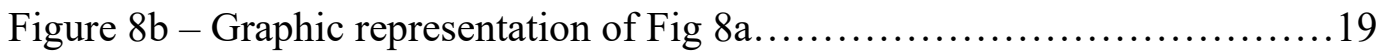

Figure 9a - Log Rank Test for Z65 cohort.............................20 
SOCIAL DETERMINANTS OF HEALTH IN PROGRESSION TO TYPE 2 DIABETES

Figure $9 b$ - Survival graph of Z65 cohort......................... 20

Figure 10a $-\mathrm{Z72}$ outcomes.........................................21

Figure $10 \mathrm{~b}-$ Graphic representation of Fig 10a......................... 21

Figure 11a - Log Rank Test of Z72 ...............................22

Figure 11b - Kaplan-Meier survival probability for Z72 cohort..............22 
SOCIAL DETERMINANTS OF HEALTH IN PROGRESSION TO TYPE 2 DIABETES

Effects of Social Determinants of Health in Progression to Type 2 Diabetes

\section{CHAPTER ONE}

\section{Introduction}

Of the estimated 400 million people in the world that have diabetes, about $90 \%$ 95\% have type 2 diabetes (Roglic, 2016). 30 million of these are Americans living with diabetes ("Division of diabetes," n.d.). Also, according to statistics reported on the Centers for Disease Control (CDC) infographic (n.d.), there are 86 million people (more than 1 out of 3 ) in the United States with prediabetes. Although not yet diagnosed with diabetes, $15-30 \%$ of prediabetics will eventually develop Type 2 diabetes within five years (CDC infographic, n.d.). Ironically, 90\% of people with prediabetes don't know they have it ("The surprising truth," n.d.).

Looking at the morbidity and mortality Type 2 diabetes can cause, with its associated economic burden, it will be necessary to identify patients with prediabetes early enough before they start having complications or even progressing to Type 2 diabetes. Division of diabetes translation documented that diabetes results in $\$ 237$ billion a year in medical cost and $\$ 90$ billion a year in lost productivity. Observational evidence shows associations of prediabetes with early forms of neuropathy, chronic kidney disease, small fiber neuropathy, diabetic retinopathy, and increased risk of macrovascular disease (Tabak, Herder, Rathmann, Brunner \& Kivimaki, 2012). The theme of this research is to identify those social determinants that predispose people with prediabetes to develop Type 2 diabetes. 
SOCIAL DETERMINANTS OF HEALTH IN PROGRESSION TO TYPE 2 DIABETES

\section{Prediabetes and Diabetes}

Diabetes is the inability of the body to process glucose properly. Glucose, or blood sugar, is a fundamental building block of the body's energy, and all human cells require glucose to live and perform their specialized functions. We get glucose from different food sources, and the pancreas is critical in glucose metabolism. The pancreas is an organ in the body that produces insulin, and insulin is required to metabolize glucose properly. Diabetes can manifest as either Type 1 or Type 2 . Type 1 diabetes is when the pancreas does not produce insulin, and this form of diabetes can be diagnosed in childhood or early adulthood. Type 1 diabetes only represents about $5 \%$ of all people with diabetes. Type 1 diabetes is caused by an immune reaction and can't be prevented at this time.

In Type 2 diabetes, the pancreas produces insulin, but there is either insulin resistance or insufficient production; the result is that the body does not metabolize glucose properly. Type 2 diabetes was formerly known as "adult-onset diabetes" since this form was most often diagnosed later in life and was often associated with other adult diseases. Besides, it develops gradually over many years. Prediabetes can develop into T2D, but not type 1(“The surprising truth...”, n.d.). To put it succinctly, preDM occurs when a person's blood sugar levels are higher than normal but not high enough for a diagnosis of Type 2 diabetes. Experts have projected that more than 470 million people worldwide will have prediabetes by 2030 (Tabak et al, 2012).

\section{Diagnosing Prediabetes and Diabetes}

The diagnosis of diabetes is usually made from one of three laboratory blood tests, and patients frequently exhibit symptoms when diagnosed. Common symptoms of 
SOCIAL DETERMINANTS OF HEALTH IN PROGRESSION TO TYPE 2 DIABETES

diabetes include excessive thirst and urination, blurry vision, and numbness or tingling sensory changes, especially in the feet or legs. Often, patients with prediabetes may not even have any of these, and most are found out incidentally. One blood test of diabetes is a hemoglobin $(\mathrm{Hb}) \mathrm{A} 1 \mathrm{C}$ level, and this test can be looked at as an average blood glucose level over time. A normal HgbA1C is less than 5.6, prediabetes is 5.7-6.4, and diabetics typically have an $\mathrm{HbA} 1 \mathrm{C}$ level of greater than 6.5. The other two tests are the fasting blood glucose level, and the oral glucose tolerance test. For this research, it is limited to using $\operatorname{HgA} 1 \mathrm{c}$ as our laboratory metric.

\section{Background of the problem}

\section{Social Determinants and Prediabetes}

Social Determinants of Health $(\mathrm{SDoH})$ are the conditions in which individuals are born, grow, live, work, and age. We are beginning to see relationships between these social determinants and the increasing incidence of Type 2 diabetes in the U.S., as well as the opportunities they present for us to counter it.

Increasingly, they are being recognized for their relationship to the soaring incidence of Type 2 diabetes in the US, as well as the opportunities they present for us to counter it. Many current Type 2 diabetes interventions focus on biological and behavioral factors, such as symptoms, diet, and physical activity. However, it is equally important to address the influence of physical and social environments, which may include low income, employment insecurity, low educational attainment, and poor living conditions on health outcomes (Hill, J., Nielsen, M., and Fox, M, 2013). 


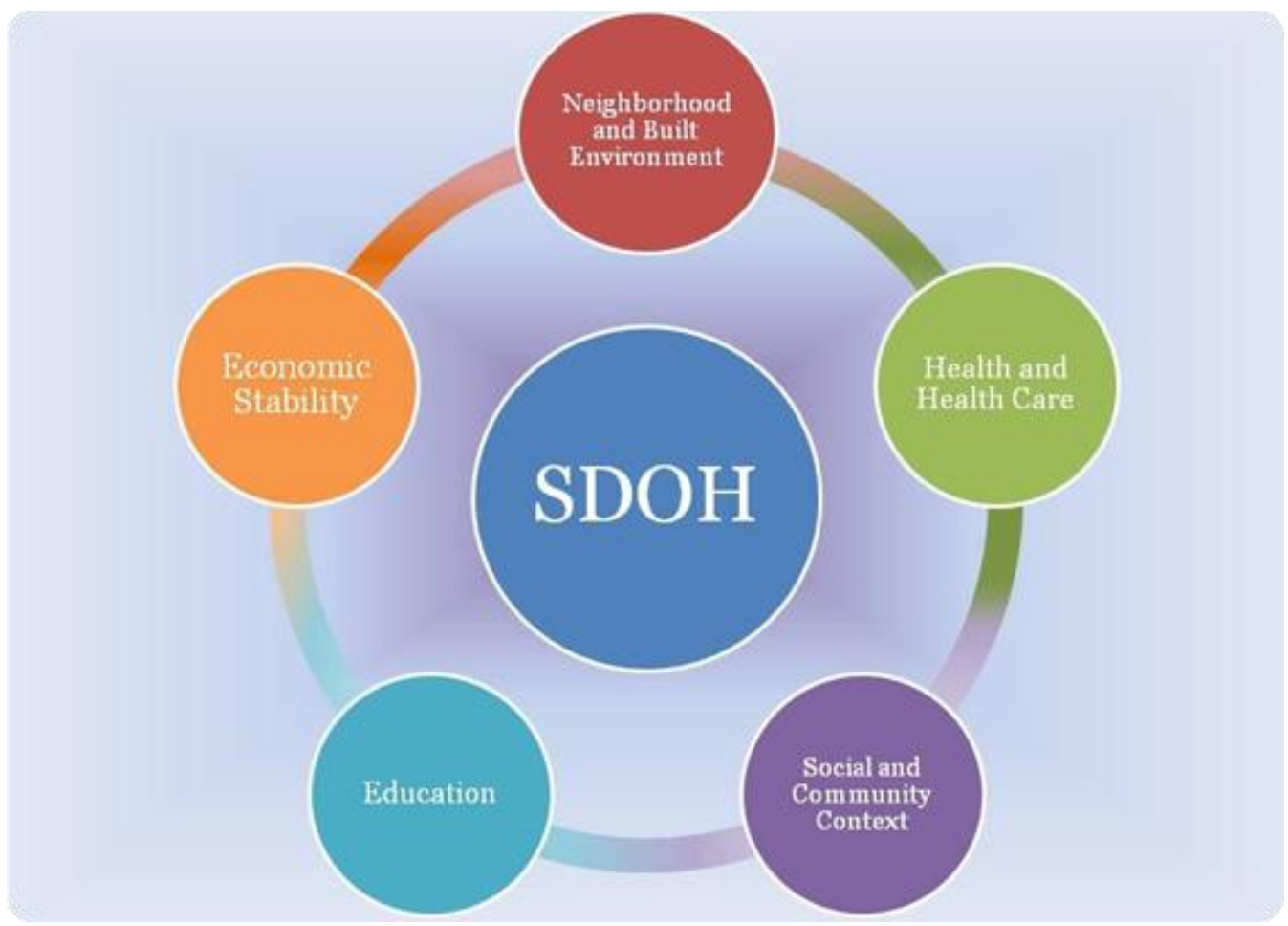

Figure 1. Components of SDoH.

Some of the social determinants to dwell on in the research are income, marital status, education level, poverty ratio, proximity to a health facility, access to recreational activities. Health insurance, which may be a function of income and education, can also be assessed as a social determinant. There are other determinants (like comorbid medical illness, medications taking for these conditions) that can contribute or predispose a patient transitioning from prediabetes to diabetes, but this research will limit it to social determinants of health. How these social determinants will affect the progression from prediabetes to Type 2 diabetes is what this research is about. SDoH has been shown to have a far greater impact on a patient's health outcomes than either the clinical care provided or genetic factors (Foley, 2021). 
SOCIAL DETERMINANTS OF HEALTH IN PROGRESSION TO TYPE 2 DIABETES

When we consider the economic burden (expense and loss in productivity), and the millions of lives involved, the quicker the diagnosis, and commencement of an effective management plan, the better it is to curb this hydra-headed disease. The purpose of this paper is to highlight how the effects of social determinants of health can lead to the progression of normoglycemia and prediabetes to Type 2 diabetes.

\section{Research Questions}

- Does exposure to SDoH predispose to progression to Type 2 diabetes?

- Which variables of SDoH lead to these progressions?

- Are those who progressed to Type 2 diabetes the same as those affected by health disparities?

\section{Definition of Terms}

- Prediabetes: intermediate stage between normal glucose level and Type 2 diabetes. HbA1c level is $5.7-6.4$

- Normoglycemia: Normal glucose/sugar level

- SDoH: Social Determinants of Health

- Z55: Problems related to and literacy

- Z56: Problems related to employment and unemployment

- Z57: Occupational exposure to risk factors

- Z59: Problems related to housing and economic circumstances

- Z60: Problems related to social environment

- Z62: Problems related to upbringing

- Z63: Other problems related to primary support group, including family circumstances 
SOCIAL DETERMINANTS OF HEALTH IN PROGRESSION TO TYPE 2 DIABETES

- Z64: Problems related to certain psychosocial circumstances

- Z65: Problems to other psychosocial circumstances

- Z72: Problems related to lifestyle

- Z75: Problems related to medical facilities and other health care

\section{Limitations of Study}

- Collection of non-medical data - health records mostly focus on medical comorbidities, but they fail to capture other records that mostly contain these SDoH.

- An incomplete collection of data - often the time when these records are collected, they are incomplete. Makes it difficult to difficult for generalizability.

Foley (2021) also agreed that HIM professionals need to ensure that SDoH information is being captured as attention is shifted towards $\mathrm{SDoH}$ to improve health quality and reduce costs. 
SOCIAL DETERMINANTS OF HEALTH IN PROGRESSION TO TYPE 2 DIABETES

\section{CHAPTER TWO}

\section{Review of Literature}

\section{Introduction}

This review is aimed at the current state of the literature on the role of the social determinants of health in the transition from prediabetes to Type 2 diabetes. Other factors like race, ethnicity, age, and sex also contribute to the progression of prediabetes to Type 2 diabetes but this will focus on the social determinants of health. Social determinants of health $(\mathrm{SDoH})$ will affect more of the process of care, quality of care, and outcomes seen in Type 2 diabetes.

\section{Methods}

This literature research was internet-based. Five major electronic databases were searched to identify relevant articles. Searches were limited to the earliest available publication date for each database to October 2019. PubMed, Scopus, CINHL, and Google Scholar. The search identified hundreds of articles. The selected articles were chosen based on articles with matching titles, potential but not enough information, and free text. The 72 that matched at least two or three of the topic tiles were scanned, 15 reviewed briskly, and 5 included in the final analysis. Most of the literature discussed more prevention of Type 2 diabetes from prediabetes using various lifestyle modifications.

\section{Population Studied.}

Although the focus was on prediabetes progression to Type 2 diabetes, many reviewed Type 2 diabetes and how complications can be reduced. Again, most of the articles are retrospective in nature, which used a lot of data already collected from events 
SOCIAL DETERMINANTS OF HEALTH IN PROGRESSION TO TYPE 2 DIABETES

at the family practitioner, hospital records, pharmacy data, and fasting blood glucose. Gary-Webb, Giachello \& Skrabak, 2014, described the built, food, school, and work environment as affecting diabetes and obesity risks.

\section{Data Extractions and Outcomes.}

The articles were reviewed, and a data extraction form was used to include details about the study quality, number of subjects, study population, as well as the description of the program. The first article (Walker, Williams, \& Egede, 2016) studied 34 systemic reviews on interventions to improve minority health found that effective intervention has the potentials to extend beyond the traditional view of clinical care coordination, culturally tailored health education, and community health workers. Larry, Greenhalgh, \& Fahy, 2018, described a meta-narrative systemic review which was carried out as desk research. They sought to explore how socio-cultural influences and risk perception contribute to health-related behaviors. Gary-Webb et al believed healthcare professionals must acknowledge and address the socioecological determinants of prediabetes and Type 2 diabetes. The fourth article (Hill, Galloway, Goley, Marrero, et al, 2013), just like the third, also believes that socioecological determinants like the biological, geographic, and build environment influence risk for prediabetes and Type 2 diabetes. Hill-Briggs, Adler, Berkowitz, Chin, et al, 2021 puts it succinctly in a fifth article that "there is SDoH evidence supporting associations of socioeconomic status, neighborhood, and physical environment."

\section{Results}

The results of the literature are presented below after carefully screening the titles. The discussion will go here. There is strong evidence that race/ethnicity and SDoH 
SOCIAL DETERMINANTS OF HEALTH IN PROGRESSION TO TYPE 2 DIABETES

impact outcomes for patients with diabetes (Walker et al, 2016). They also agreed that more research is needed to identify the separate and combined impact of race/ethnicity and $\mathrm{SDoH}$ on the process of care, quality of care, and outcomes. Other authors also agreed that clinical care alone will not be sufficient but to look inward on the social determinants of health.

\section{Summary of this Review}

Most of the literature discussed more prevention of Type 2 diabetes from prediabetes using lifestyle modifications. A pertinent question to ask is, does the data accurately capture SDoH? Even though clinical information systems can assist, they may not collect all the data on nonmedical factors. Walker et al also mentioned that many articles were only tangentially related to $\mathrm{SDoH}$. 
SOCIAL DETERMINANTS OF HEALTH IN PROGRESSION TO TYPE 2 DIABETES

\section{CHAPTER THREE}

\section{Methodology}

This research is a prospective cohort study. The data source is from TriNetX where health records are collected from millions of individuals both in ambulatory and inpatient settings. The collected data was mined and analyzed using the query design assistance of the TriNetX platform.

Population and Sample Design: the target population is adults (aged $>=18$ years) who have normal glucose levels or those diagnosed with prediabetes. The main theme of the research is the impact SDoH might have on the development of Type 2 diabetes. A cohort was exposed to these $\mathrm{SDoH}$ as an inclusion criterion. The exposure years were from $1 / 1 / 2014$ to $12 / 31 / 2016$. It attempted to mimic the use of "ICD-10 Z-codes" which didn't come into existent in the United States until 1/10/2015. While the control (non-exposed) cohort had the same set of SDoH as an exclusion criterion. The Health data of these patients were reviewed for 2016 from the TriNetX dataset as the base year. It excluded those with a diagnosis of type 2 diabetes from the base year. Those who progress to type 2 diabetes would be reviewed, and the possible SDoH that could predispose them will be noted. They were then followed up for the next four years (2017 to 2020) and the outcomes measured using these records. This research was done over two semesters.

Data Collection Procedures: These data were collected mainly from hospital networks (campuses and institutions) in Tennessee through TriNetX. Because this collection is a continuum, more institutions are planned to be added in the future. Thus, the data keep rolling. 
SOCIAL DETERMINANTS OF HEALTH IN PROGRESSION TO TYPE 2 DIABETES

Data Collection Instrument: The TriNetX is a global health research network platform that connects multiple healthcare organizations (HCO). TriNetX for this research has only one HCO on the network which is the Clinical Trials Network of Tennessee. Data collection on this network dates to 2014 till date. It has over 1.6 million patients on the network which has its headquarters in Memphis, TN. It contains a wide array of data that includes but is not limited to pediatric and oncology patients. It also features different laboratory investigations which include the HbA1c primary used in this research as a diagnostic metric.

Data Analysis: TriNetX was used to analyze the data. It allows one to compare cohorts before index event, incidence, and prevalence as well as compare outcome analysis. The beauty of the TriNetX is its ability to make possible the following analyses, risk difference, risk ratio, odds ratio, p-value, Kaplan-Meier survival curve.

The primary outcome measure was HbA1c $>6.5$ (Type 2 diabetes). Secondary outcomes measures were $\mathrm{SDoH}$ variables with $\mathrm{HbA1c}>6.5$. Statistical analysis was performed with the Student $t$-test. Survival probability was done using the log-rank, all done through TriNetX. 
SOCIAL DETERMINANTS OF HEALTH IN PROGRESSION TO TYPE 2 DIABETES

\section{CHAPTER FOUR}

\section{Results}

After applying our inclusion and exclusion criteria hundred and seventy (170) patients were identified in the exposed cohort (Figure 2) and fifteen thousand and ten participants resulted for the non-exposed cohort (Figure 3) after a four-year follow-up from 2017 to 2020 .

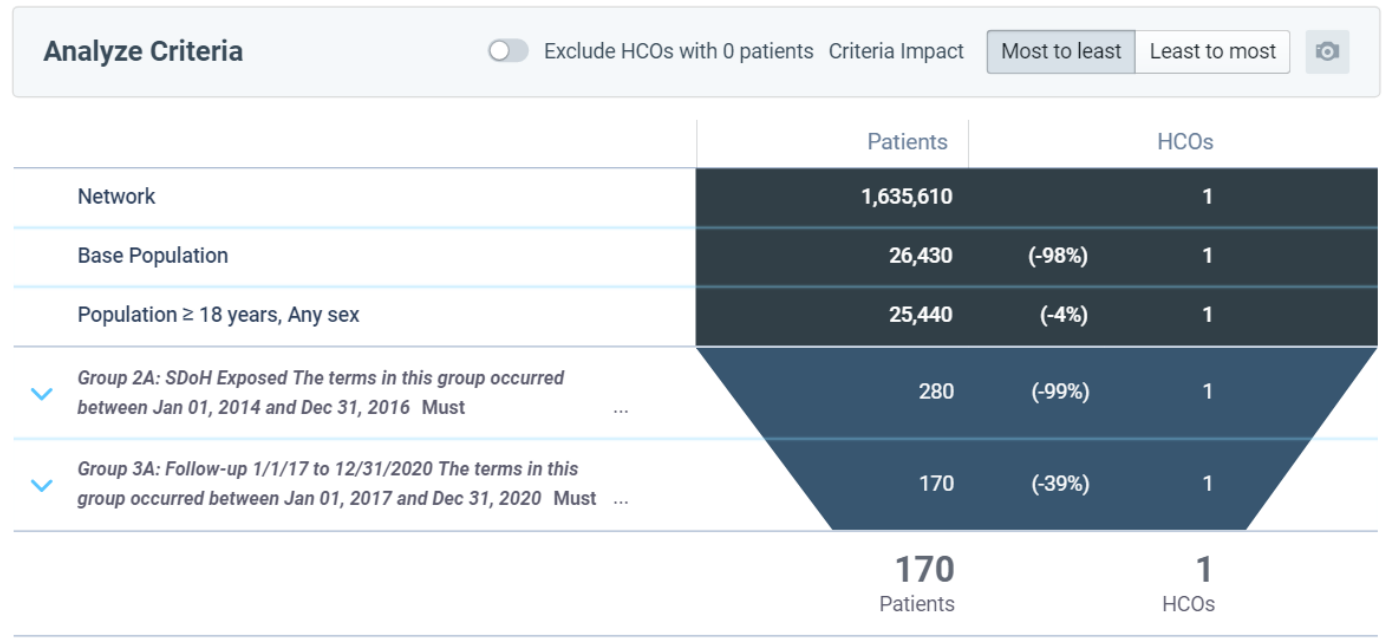

These terms were selected in base population

MUST Have:

CANNOT Have:

Group 1A: Baseline The terms in this group occurred between Jan 01, 2016 and Dec 31, 2016

9037 Hemoglobin A1c/Hemoglobin.total in Blood $[\leq 6.4 \%$, ever]

OR R73.03 Prediabetes

Figure 2 - Exposed Cohort after four-year follow-up. 
SOCIAL DETERMINANTS OF HEALTH IN PROGRESSION TO TYPE 2 DIABETES

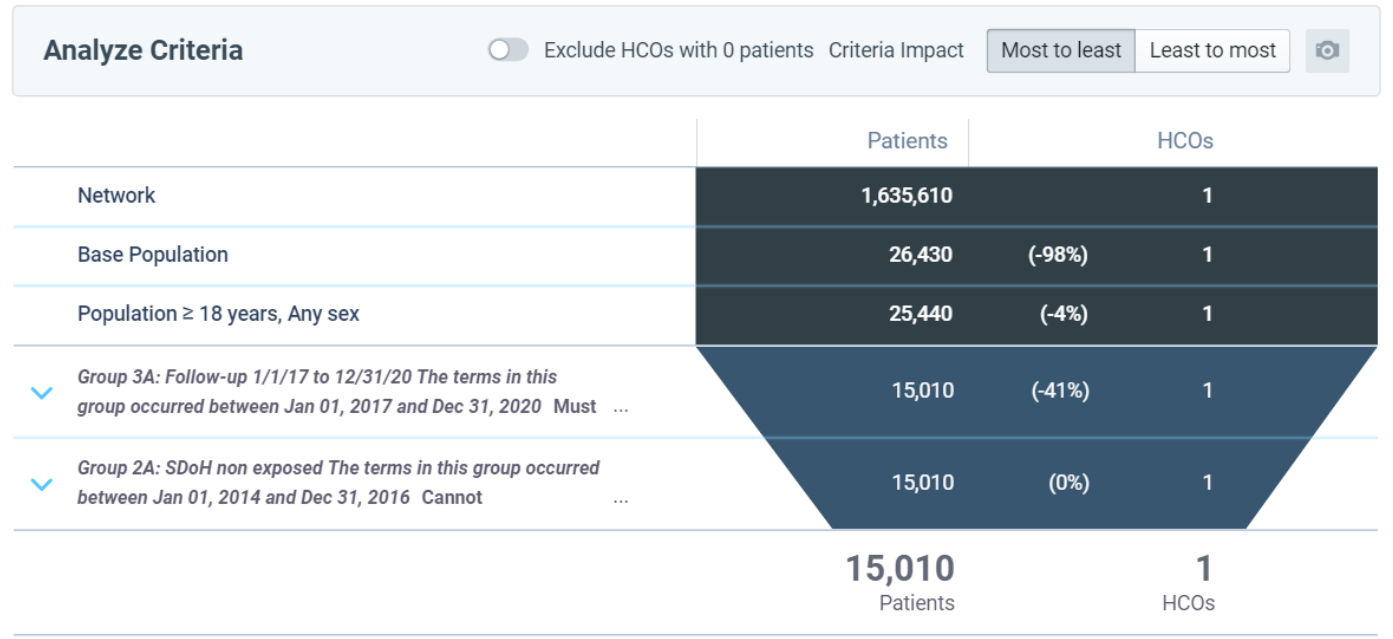

These terms were selected in base population

MUST Have: $\quad$ CANNOT Have:

Group 1A: Baseline The terms in this group occurred between Jan 01, 2016 and Dec 31, 2016

9037 Hemoglobin A1c/Hemoglobin.total in Blood $[\leq 6.4 \%$, ever]

OR R73.03 Prediabetes

Figure 3 - Non-exposed cohort after four-year follow-up.

Demography (Figure 4) of the exposed showed that there are $70 \%$ females in the cohort and $29 \%$ males. It also revealed that $58 \%$ of these were of African American descent, $41 \%$ were Caucasians, and other races making up the numbers. $94 \%$ have nonHispanic or Latino as their ethnicity. 


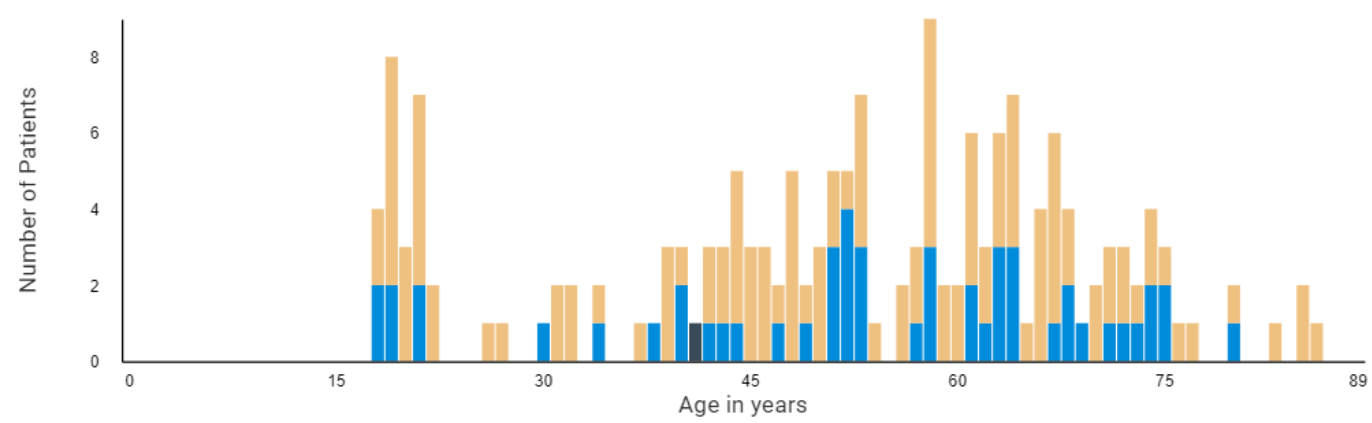

\begin{tabular}{|r|r|r|r|r|} 
& & & Patients 90 and Older: 0 \\
\hline Total Patients & Minimum Age & Maximum Age & Mean Age & Standard Deviation \\
\hline 170 & $\mathbf{1 8}$ & $\mathbf{8 6}$ & $\mathbf{5 2}$ & $\mathbf{1 8}$ \\
\hline
\end{tabular}
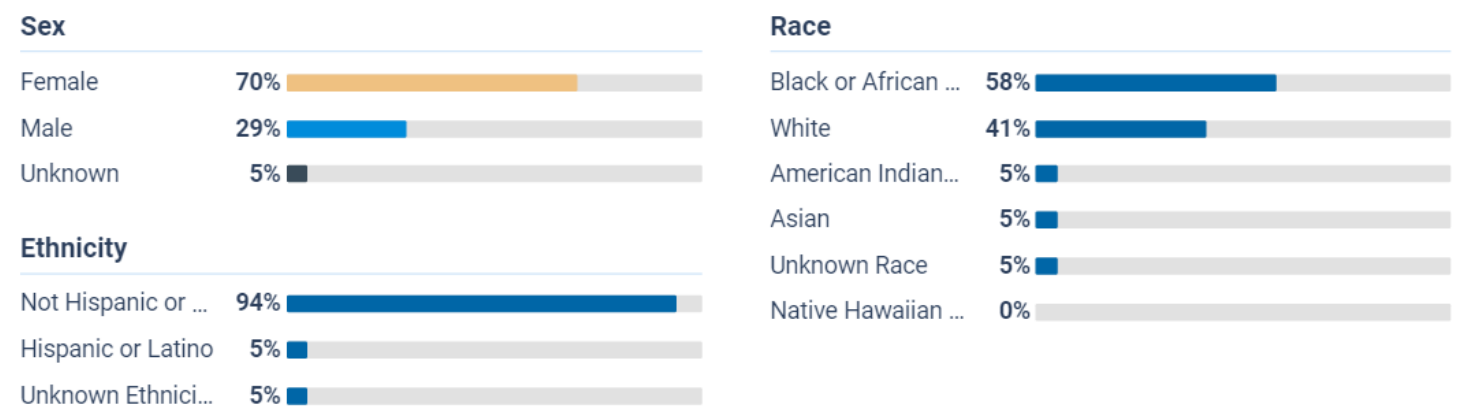

Figure 4 - Demography of exposed cohort.

The non-exposed cohort however didn't show a preference for any gender, with $58 \%$ being females and $42 \%$ males. There is also a reversal in the distribution of the races with $52 \%$ Caucasians in the cohort. Again, non-Hispanic or Latino was the ethnicity of most participants. 


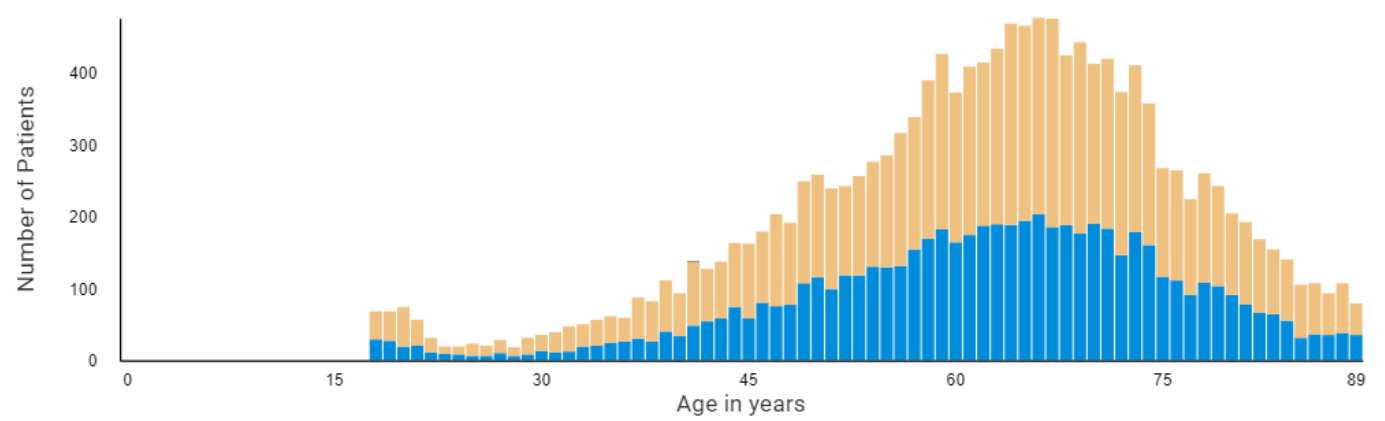

Patients 90 and Older: 307

\begin{tabular}{|r|r|r|r|r|}
\hline Total Patients & Minimum Age & Maximum Age & Mean Age & Standard Deviation \\
\hline 15,010 & 18 & 90 & 62 & 15 \\
\hline
\end{tabular}

\begin{tabular}{lr} 
Sex & \\
Female & $58 \%$ \\
Male & $42 \%$ \\
Unknown & \\
Ethnicity & \\
\hline Not Hispanic or ... & $97 \%$ \\
Unknown Ethnici... & $\mathbf{2} \%$ \\
Hispanic or Latino & $\mathbf{1} \% \mathrm{I}$
\end{tabular}

Race

White

Black or African ...

Unknown Race

Asian

American Indian..

Native Hawaiian ..

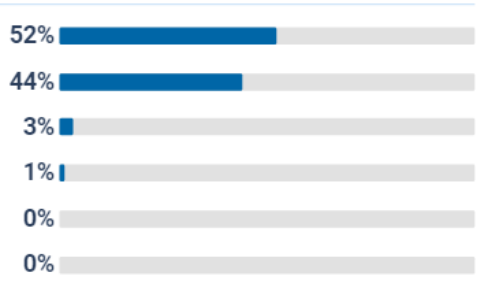

Generated by TriNetX

Figure 5 - Demography of non-exposed Cohort.

On applying our outcome measure which is $\mathrm{HbA1c}>6.5$ (Type 2 diabetes), below are the primary and secondary outcomes.

\section{Primary Outcome}

- There was an increased risk of developing Type $2 \mathrm{DM}$ in the non-exposed group contrary to expectation and literature review support ( $24 \%$ vs $28 \%, \mathrm{p}=0.22)$. 
Figures $6 \mathrm{a}$ and $6 \mathrm{~b}$ bellowed showed the statistical analysis of the primary outcome as well as the graphic representation.

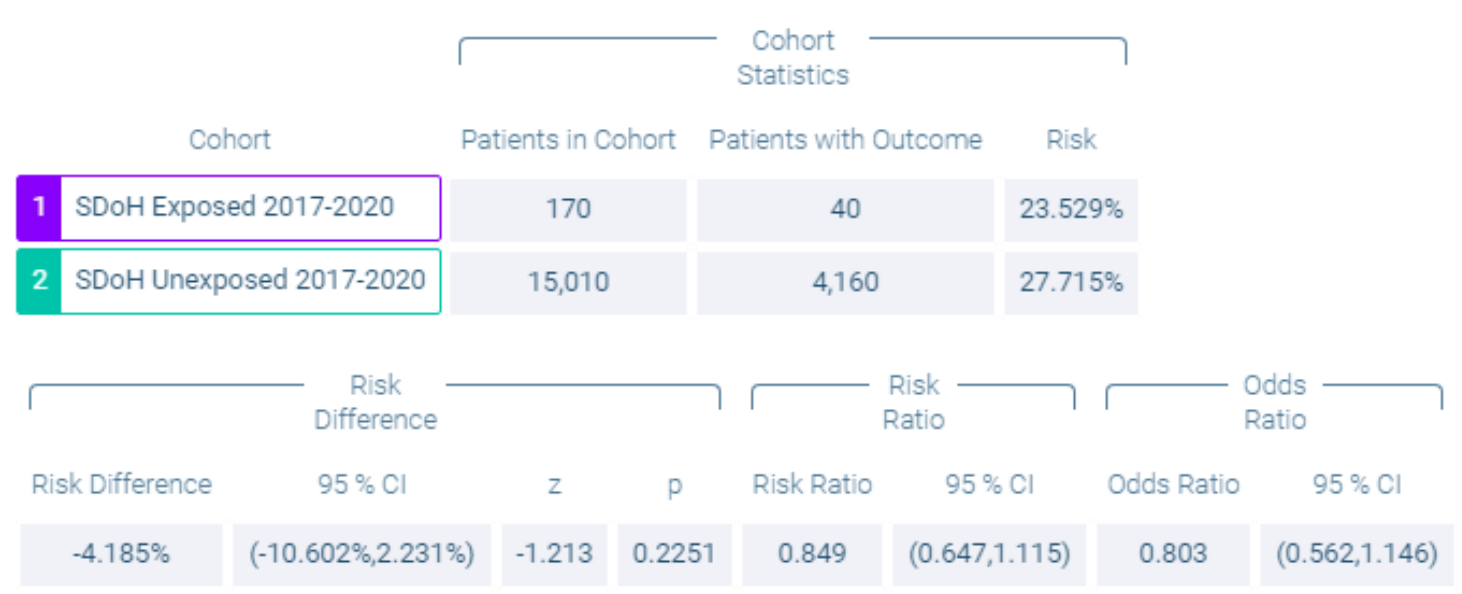

Figure $6 \mathrm{a}-$ Risk difference of the primary outcome.

Risk of Outcome
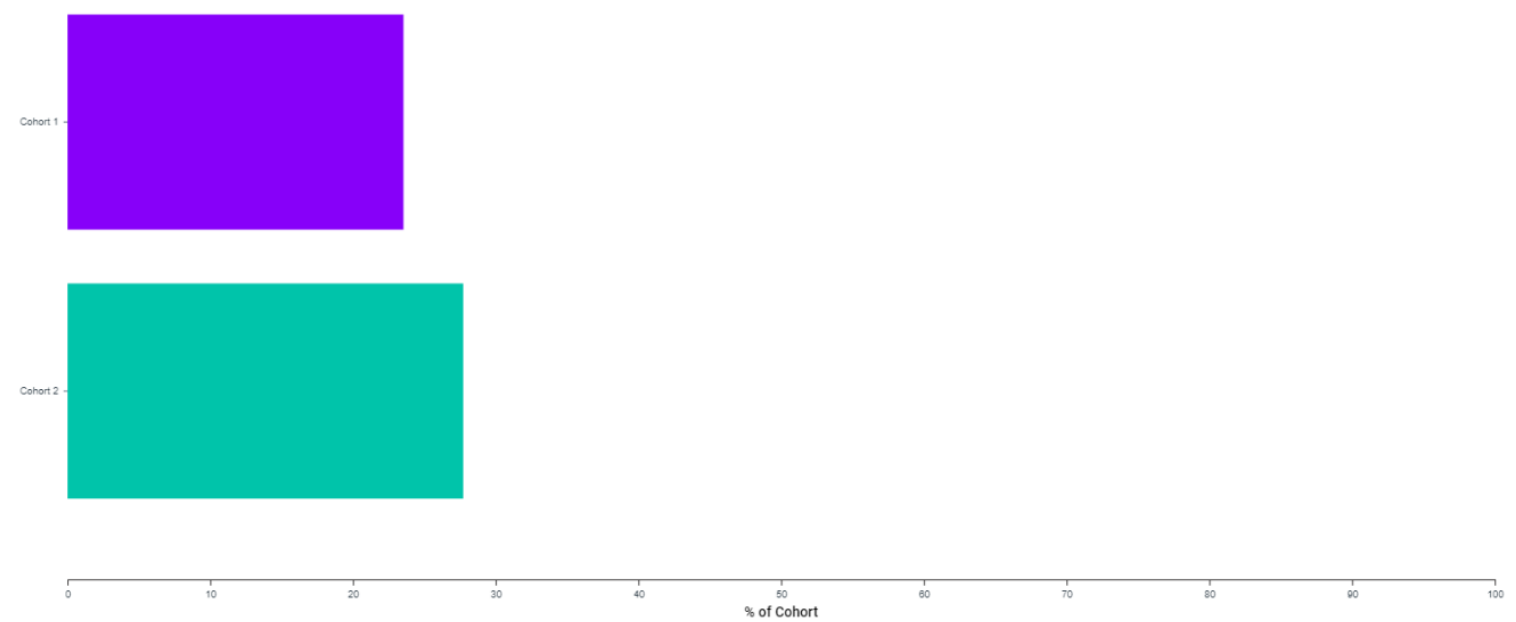

Figure $6 b-$ Graphic representation of fig. $6 a$ above. 
- Survival probability was also better amongst those that were exposed, surprisingly (72\% vs 59\%, $\mathrm{p}=0.012)$, it was significant (see Figure $7 \mathrm{a}$ and $7 \mathrm{~b}$ ).

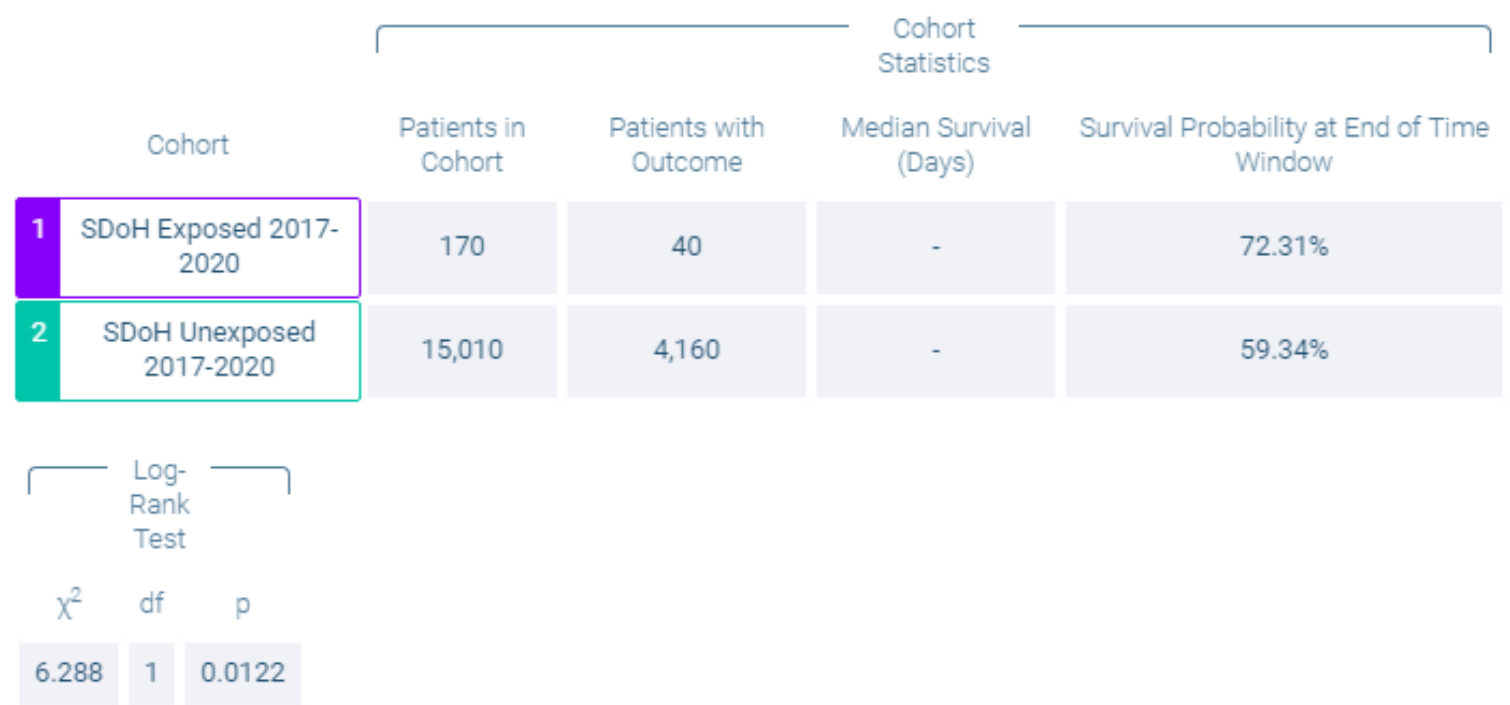

Figure 7a-Log-Rank Test of the primary outcome.

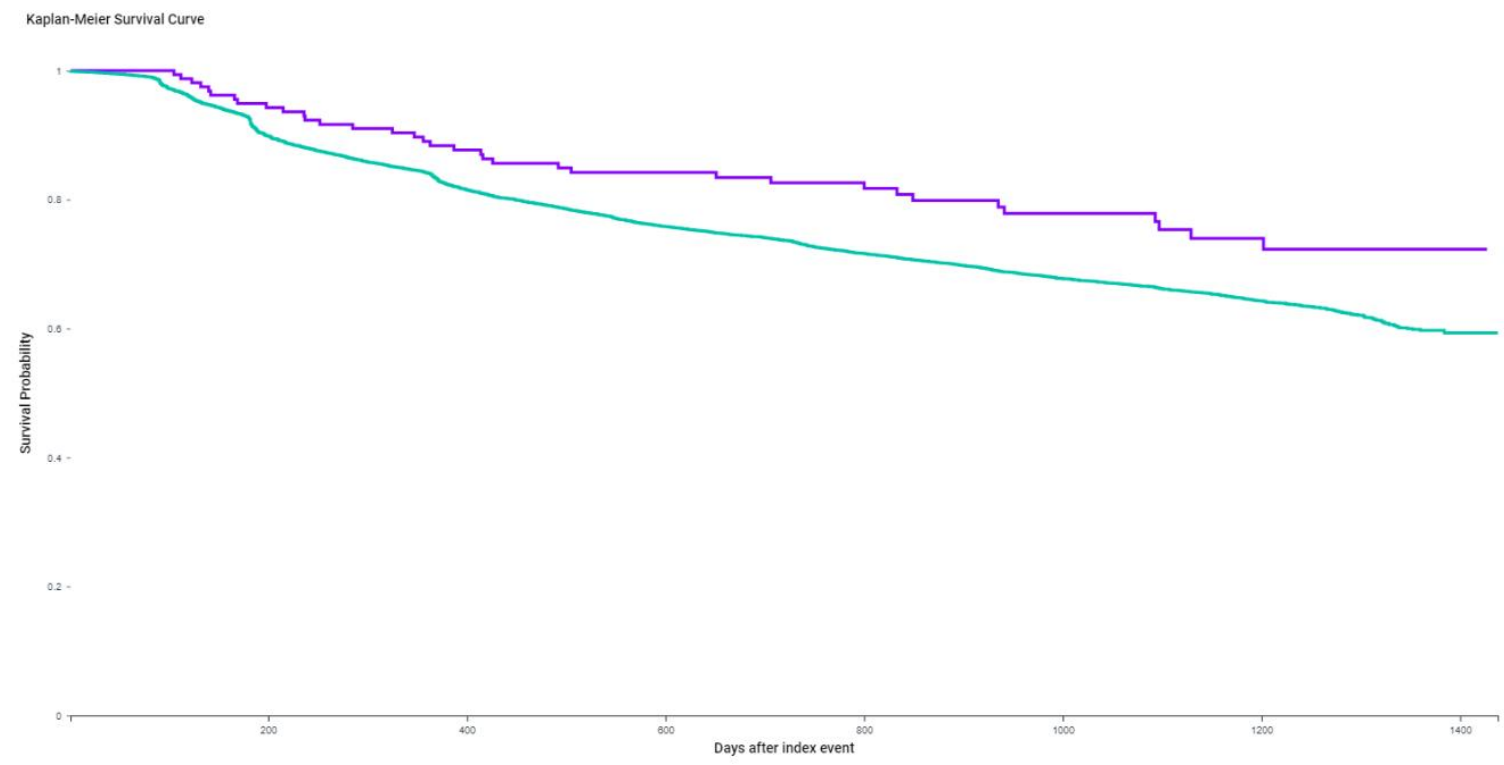

Figure $7 b$ - Kaplan-Meier Curve for the primary outcome. 
Some of the SDoH variables, Z65 and Z70 were the two that TriNetX could analyze. Although, there were cohorts for Z59, Z60, Z63, and Z64 however it was too narrow for analysis. Figure 8 below shows the number for each cohort after applying the outcome measure $(\mathrm{HbA1c}>6.5)$.

\begin{tabular}{|l|c|c|}
\hline \multicolumn{1}{|c|}{ SDoH ICD-10 Z- codes } & Exposed Cohort & Non-Exposed \\
\hline Z55: Problems related to education and literacy & 0 & 15,010 \\
\hline $\begin{array}{l}\text { Z56: Problems related to employment and } \\
\text { unemployment }\end{array}$ & 0 & 15,010 \\
\hline Z57: Occupational exposure to risk factors & 0 & 15,010 \\
\hline $\begin{array}{l}\text { Z59: Problems related to housing and economic } \\
\text { circumstances }\end{array}$ & 10 & 15,010 \\
\hline Z60: Problems related to social environment & 10 & 15,010 \\
\hline Z62: Problems related to upbringing & 0 & 15,010 \\
\hline $\begin{array}{l}\text { Z63: Other problems related to primary support } \\
\text { group, including family circumstances }\end{array}$ & 10 & 15,010 \\
\hline $\begin{array}{l}\text { Z64: Problems related to certain psychosocial } \\
\text { circumstances }\end{array}$ & 10 & 15,010 \\
\hline $\begin{array}{l}\text { Z65: Problems to other psychosocial } \\
\text { circumstances }\end{array}$ & 100 & 15,010 \\
\hline Z72: Problems related to lifestyle & 70 & 15,010 \\
\hline $\begin{array}{l}\text { Z75: Problems related to medical facilities and } \\
\text { other health care }\end{array}$ & 0 & 15,010 \\
\hline
\end{tabular}

Table 1 showing the number of patients in the different SDoH variables after using the outcome measure.

\section{Secondary Outcome}

- Problems related to other psychosocial circumstances (Z65): more risk (30\% vs $27.7 \%, \mathrm{p}=0.61)$ of the outcome (Type 2 diabetes) in the exposed group (figure $8 \mathrm{a}$ and $8 b$ ) but their survival probability (figure $9 \mathrm{a}$ and $9 \mathrm{~b})$ was better ( $67 \%$ vs $59 \%$, 
$p=0.193)$ when compared to the non-exposed cohort. They however do not differ significantly.

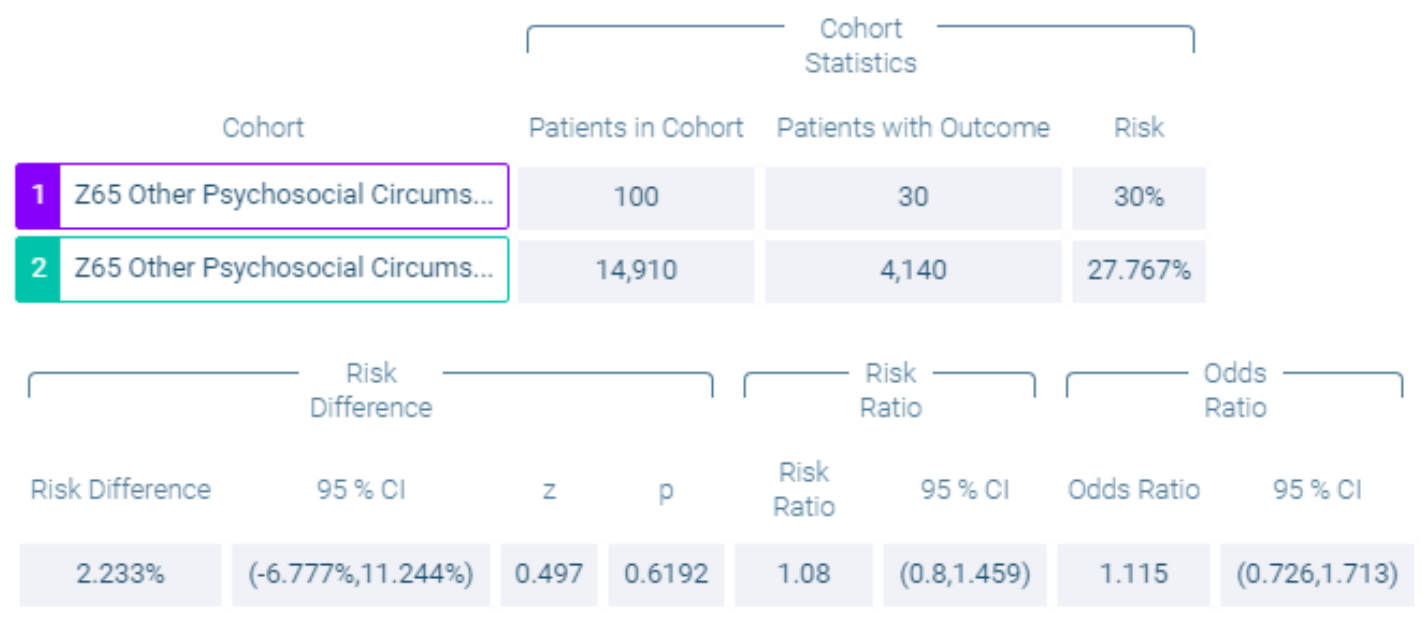

Figure $8 \mathrm{a}-$ Z65 outcomes for problems related to other psychosocial circumstances.
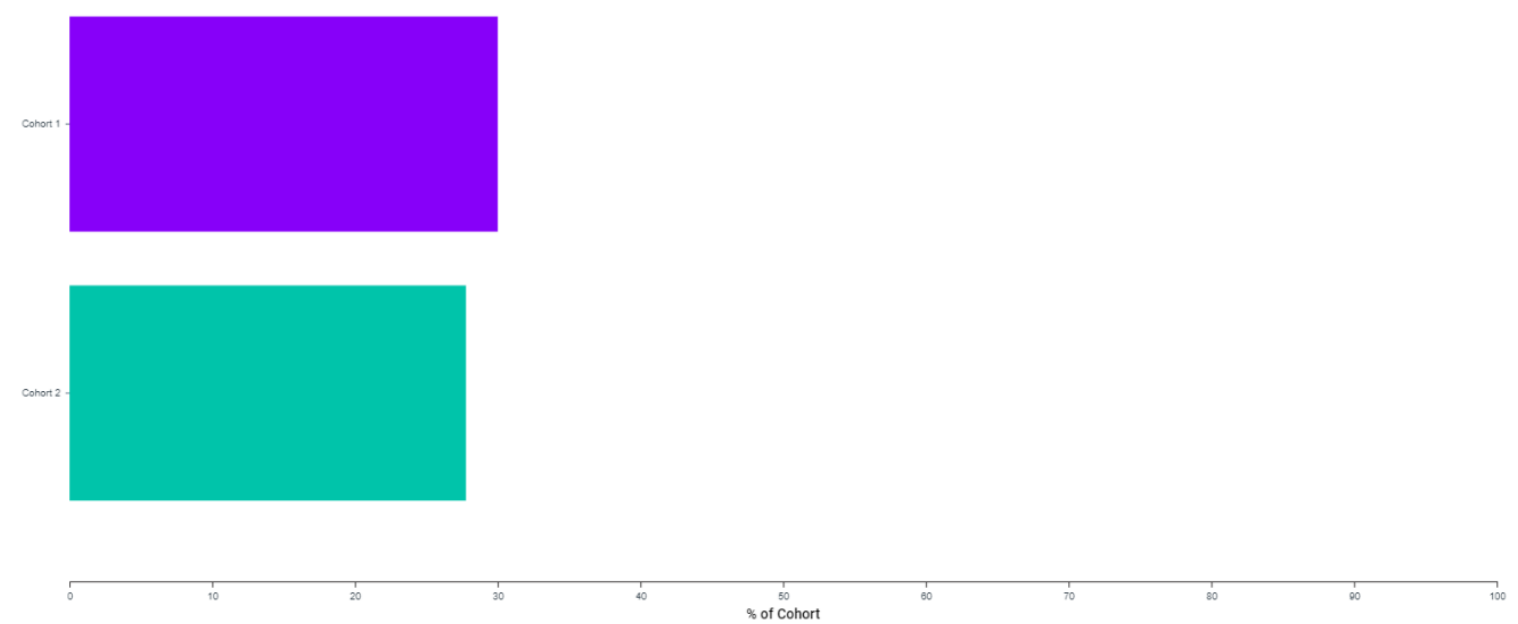

Figure $8 b-$ Graphic representation of problems related to other psychosocial circumstances. 
SOCIAL DETERMINANTS OF HEALTH IN PROGRESSION TO TYPE 2 DIABETES

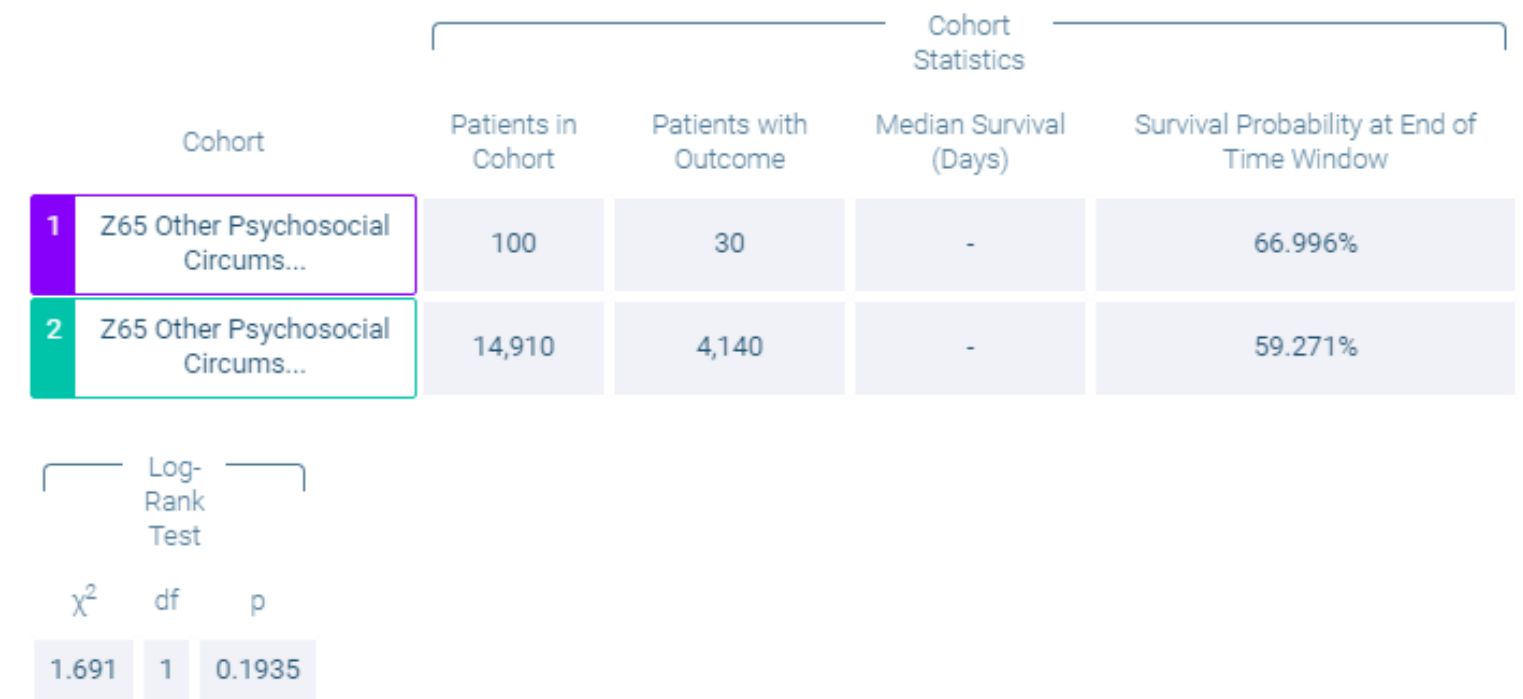

Figure 9a - Log Rank Test for Z65 cohort.

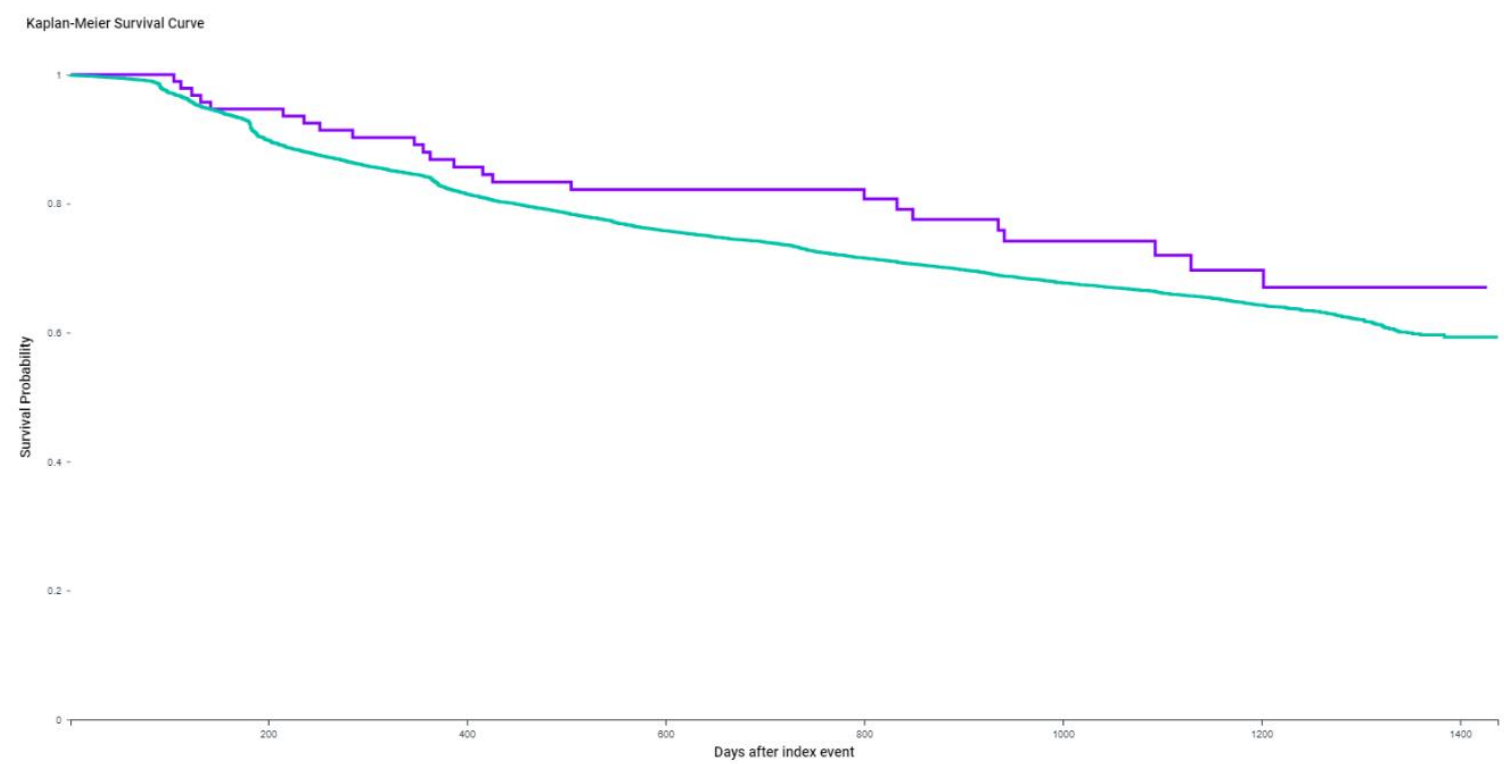

Figure $9 b$ - Survival probability graph of Z65 cohort. 
- Problems related to lifestyle (Z72): interestingly, the risk of outcome is doubled $(28 \%$ vs $14 \%, p=0.011)$ in non-exposed which is significant (figures $10 \mathrm{a}$ and $10 b)$.

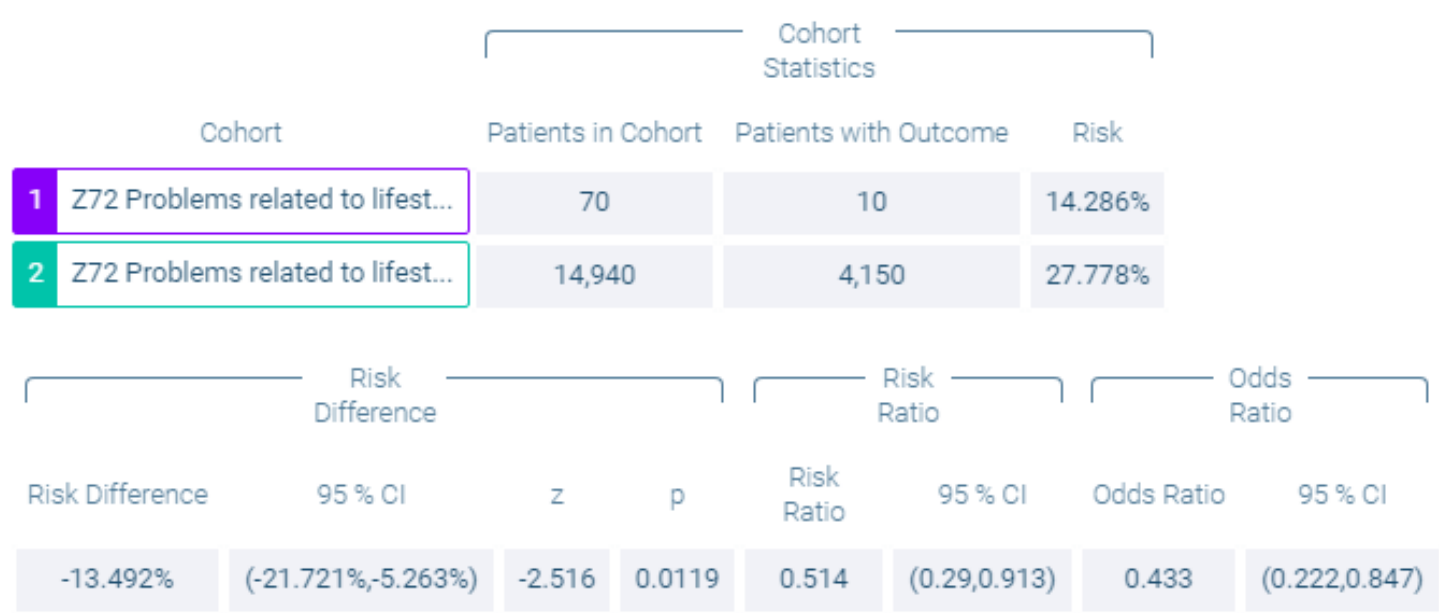

Figure 10a-Z72 outcomes for problems related to lifestyle.
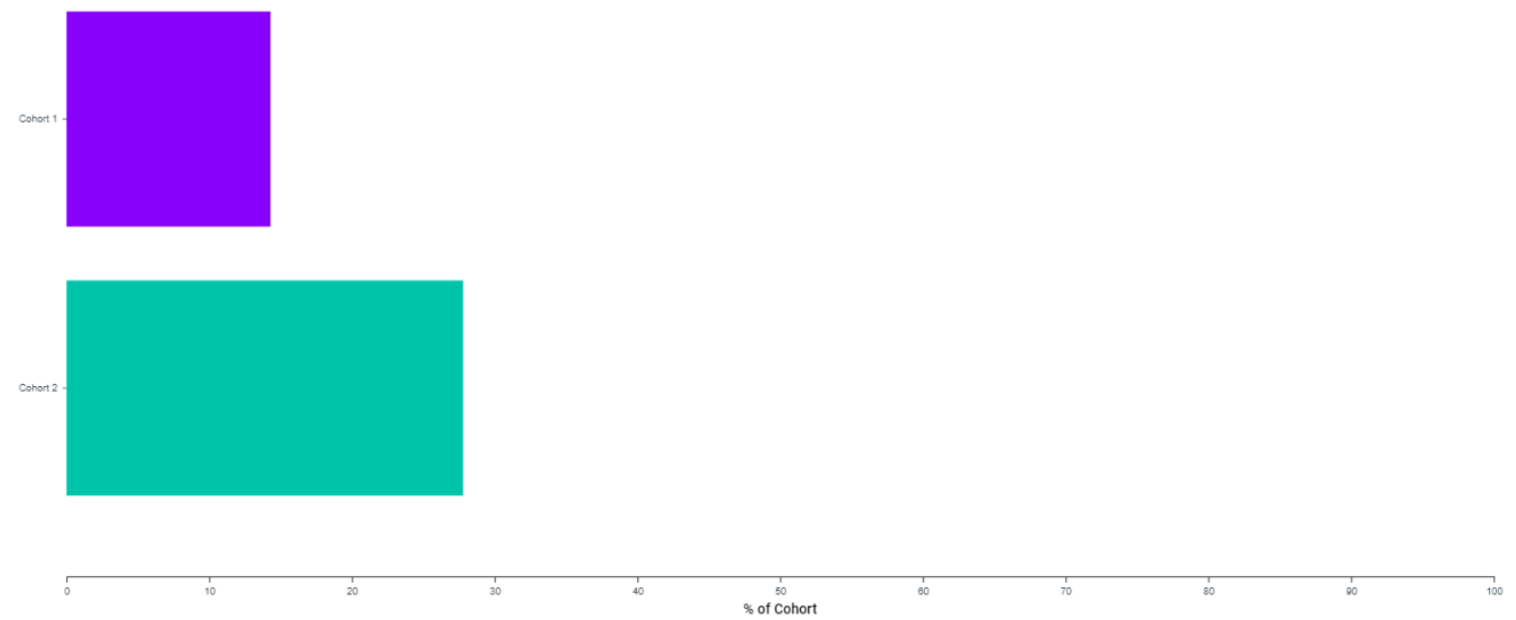

Figure $10 b-$ Graphic representation of problems related to lifestyle. 
- Figures 11a and $11 \mathrm{~b}$ shows that the exposed cohort also holds the advantage in survival probability even to a greater extent $(81 \%$ vs $59 \%, \mathrm{p}=0.015)$ and clinically significant.

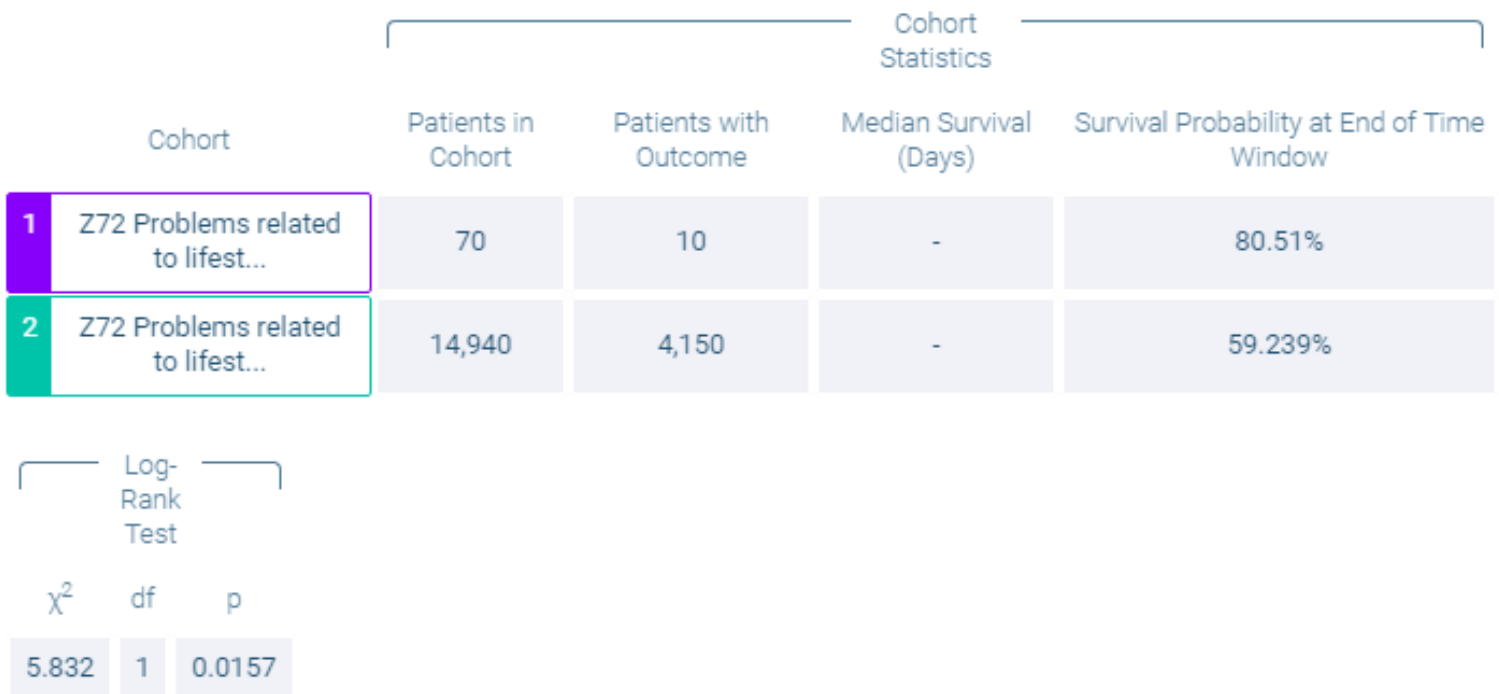

Figure 11a - Log Rank test of Z72

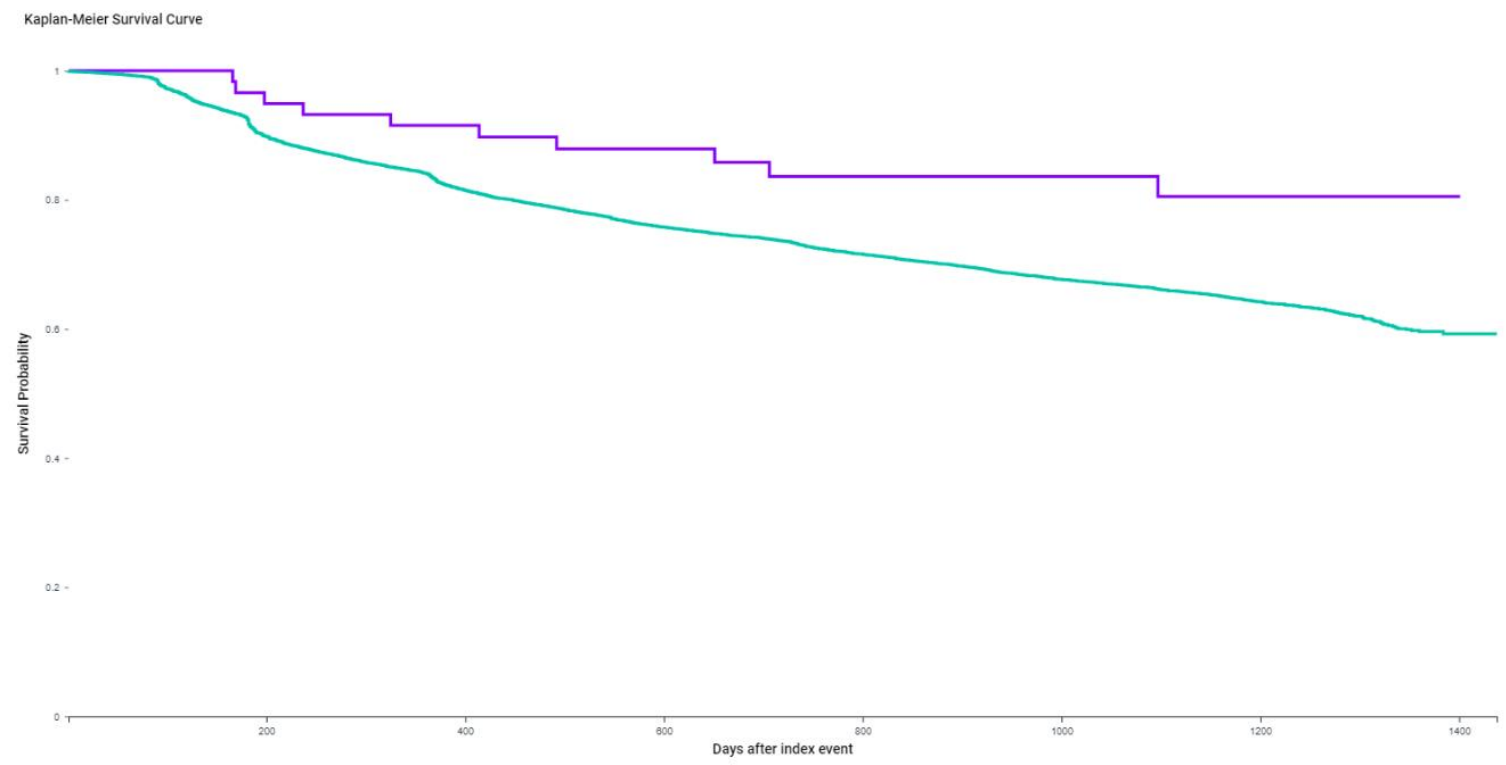

Figure 11b- Kaplan-Meier survival probability for Z72 cohort 


\section{Results of Research Questions:}

- Does exposure to $\mathrm{SDoH}$ predispose to progression to type 2 diabetes? Our hypothesis wasn't answered. The exposed cohort seems to do better following the primary outcome.

- Which variables of SDoH lead to these progressions? The Z65 and Z72 showed some analyzable results but the result was contrary to our hypothesis that the exposed cohort would be more at risk and should also have poor survival probability.

- Are those who progressed to Type 2 diabetes the same as those affected by health disparities? TriNetX wasn't able to provide post-outcome demography to compare this. This could be due to user-dependent.

The plausible explanation is that the exposed cohort sought medical care having realized their disadvantages. Health care providers too probably followed them up closely on identifying some of these SDoH.

\section{CHAPTER FIVE}

\section{Summary, Conclusion, and Recommendations}

This chapter will cover the summary findings of my applied research on the topic. The reason for choosing this topic is centered on how the cost implication of the effects of type 2 diabetes has on our economy. It is a prospective cohort study that used already 
SOCIAL DETERMINANTS OF HEALTH IN PROGRESSION TO TYPE 2 DIABETES

collected data using the TriNetX platform and the patients followed prospectively for four years $(2017-2020)$.

\section{Discussions}

Type 2 diabetes is a complex, polygenic disease that increases a patient's likelihood of developing many complications. It has been shown that patients develop some complications during the time of being diagnosed with prediabetes. These complications add to morbidity and mortality associated with type 2 diabetes. The earlier patients with prediabetes are identified and effective management commenced, the better to prevent or delay the onset of type 2 diabetes and its attendant economic burden.

\section{Primary Outcome}

The main this research asked was only tangentially related to the results found. The primary outcome showed there is a slightly increased risk of developing Type 2 diabetes in the non-exposed group contrary to our hypothesis. The survival probability profile was also better and clinically significant.

\section{Secondary Outcomes}

Those who have problems related to lifestyle $(\mathrm{Z} 72)$ resulted in a risk that doubled that of the exposed cohort of this SDoH variable as well as a better survival probability to an even greater extent. Both were clinically significant.

Amongst the Z65 cohort of SDoH, expectedly, the risk of outcome in the exposed group was more but for some reason, they have better survival probability when compared to the non-exposed group. The likely reason could be that their exposure made them seek medical attention. This in turn puts them up for closer monitoring and followup that possibly resulted in better outcomes. 
SOCIAL DETERMINANTS OF HEALTH IN PROGRESSION TO TYPE 2 DIABETES

Our results were probably limited by the way the SDoH data was collected. AHIMA in one of its journals (Fiala, 2019), also reported that SDoH "are among the most influential factors that determine health outcomes of individuals". So, capturing these data is rapidly becoming a necessary element of documentation.

Structured lifestyle changes, as outlined by the National Diabetes Prevention Program (National DPP) such as weight loss, exercise, and a healthy diet, are known to reduce the risk of conversion from prediabetes to Type 2 diabetes. The CDC infographic (n.d.) also points out that these structured lifestyle changes can cut the progression to type 2 diabetes in half. Prediabetes is real, common, but most importantly, it is reversible through proven lifestyle changes. Prediabetes may be a risk factor in developing type 2 diabetes; it must be emphasized that it remains a serious concern that would not lessen without intervention.

\section{Conclusion}

- Although this research failed to demonstrate the longitudinal association between Social Determinants of Health and progression to Type 2 diabetes there are positives from it.

- Exposure to some of these SDoH could make patients seek care more and such visits could mean they get more attention, hence diminishing these effects.

\section{Recommendations}

- Collection of accurate and complete nonmedical data (SDoH) to enhance health policies and current interventions. 
- ICD-10-CM codes specifically reflect different domains of SDoH. This will help to stratify these data at the primary collection level and will further help to effect the right changes when making policies.

- Policies that both interest public health principles and practice, and promote the linkage of SDoH to health care delivery

- Policy development to effectively identify the population at risk for developing type 2 diabetes.

- Promoting health education among people of lower socioeconomic status.

- Healthcare professionals must acknowledge and address the socioecological determinants of prediabetes and type 2 diabetes. 
SOCIAL DETERMINANTS OF HEALTH IN PROGRESSION TO TYPE 2 DIABETES

\section{References}

Barry, E, Greenhalgh, T., and Fahy, N. (2018). How are health-related behaviours influenced by a diagnosis of pre-diabetes: A meta-narrative review. $B M C$ Medicine, 16(1):121. doi.org/10.1186/s12916-018-1107-6.

CDC - About the Program - National Diabetes Prevention Program - Diabetes DDT. Retrieved from https://www.cdc.gov/diabetes/prevention/pdf/NDPP_Infographic.pdf

Division of diabetes translation at a glance. Retrieved from https://www.cdc.gov/chronicdisease/resources/publications/aag/diabetes.htm (Updated August 7, 2019).

Fiala, W.C (2019). Reporting social determinants of health. Journal of AHIMA. Retrieved from https://journal.ahima.org/reporting-social-determinants-of-health/

Foley, M.M (2021). Improving ICD-10-CM coding for social determinants of health. Journal of AHIMA. Retrieved from https://journal.ahima.org/improving-icd-10cm-coding-for-social-determinants-of-health/

Gary-Webb, T., Maisonet Giachello, A.L., Maier, K., and Skrabak, H. (2014). Socioecological determinants of prediabetes and type 2 diabetes: Agenda for action. Clinical Diabetes, 32(3): 140-143. doi: 10.2337/diaclin.32.3.140.

Hill, J.O., Galloway, J.M., Goley, A, Marrero, D.G., Minners, R....and Aroda, V. R. (2013). Scientific statement: Socioecological determinant of prediabetes and type 2 diabetes. Diabetes Care, 36(8): 2430-2439. doi: 10.2337/dc13-1161 
SOCIAL DETERMINANTS OF HEALTH IN PROGRESSION TO TYPE 2 DIABETES

Hill, J., Nielsen, M., and Fox, M. (2013). Understanding the social factors that contribute to diabetes: A means to informing health care and social policies for the chronically ill. The Permanente Journal, 17(2):67-72. doi: 10.7812/TPP/12-099.

Hill-Briggs, F., Adler, N.E., Berkowitz, S.A., Chin, M.H., Gary-Webb, T.L.....and HaireJoshu. (2021). Social determinants of health and diabetes: A scientific review.

Diabetes Care Jan 2021, 44 (1) 258-279; doi: 10.2337/dci20-0053

Roglic, G. (2016). WHO global report on diabetes: A summary. Int J Non-Commun Dis 1:3-8.

Tabak, A.G., Herder, C., Rathman, W., Brunner, E.J., and Kivimaki, M. (2012). Prediabetes: A high-risk state for developing diabetes. The Lancet, 379(9833):2279-2290.

The surprising truth about prediabetes. (n.d). Retrieved from https://www.cdc.gov/features/diabetesprevention/index.html (Updated January 12, 2018)

Walker, R.J., Williams, J.S., and Egede, L.E. (2016). Impact of race/ethnicity and social determinants of health on diabetic outcomes. Am J Med Sci, 351(4): 366-373. doi: 10.1016/j.amjms.2016.01.008 